\title{
RELATOS DE REFUGIADOS NORTE-COREANOS: HISTÓRIA ORAL E NARRATIVAS AUTOBIOGRÁFICAS
}

\author{
VALÉRIA BARBOSA DE MAGALHÃES \\ Universidade de São Paulo
}

RESUMO Este artigo analisa algumas imprecisões narrativas em um conjunto de relatos autobiográficos de refugiados norte-coreanos divulgados em fontes midiáticas e livros, tomando por base os recursos da história oral e o entendimento de aspectos da memória coletiva e da identidade. 0 caminho do texto mostrará que, para além das inexatidões, as narrativas revelam uma tentativa de afirmação da identidade no exílio. A história de Yeonmi Park será o ponto de partida para a discussão, analisada ao lado de outros casos. Algumas questões clássicas da história oral permeiam a argumentação: seriam as falhas na memória indicativas de que um narrador está mentindo? Como os pesquisadores de história oral lidam com as inconsistências nas entrevistas com as quais trabalham? Quais os recursos da história oral para enfrentar as eventuais imprecisões dos depoimentos e quais os seus significados? A metodologia utilizada foi a história oral com uso de fontes secundárias. Os relatos foram analisados a partir da técnica de fichamento temático. As narrativas aqui apresentadas parecem ter um papel relevante na construção da identidade do deslocamento de norte-coreanos e constituem um recurso de história pública "feita pelo público".

Palavras-chave: Refugiados norte-coreanos. Verdade em História Oral. Identidade e Memória.

ABSTRACT NORTH-KOREAN DEFECTOR'S NARRATIVES: ORAL HISTORY AND AUTOBIOGRAPHICAL NARRATIVES

Interviews and autobiographical narratives of North Korean refugees - that are largely available in the media and books - are the starting point for the discussion we propose in this article. The analyzed case is the story of Yeonmi Park, besides other examples. Our intention is to contribute to the debate about truth in oral history. Do the failures in memory indicate that the narrator is lying? How should oral history researchers deal with the inconsistencies in the accounts they work with? We will highlight the importance of 
narratives for the construction of a collective identity of displacement and also as a resource for public history. The paper presents some ideas on how oral history can deal with the testimonial's inaccuracies.

Keywords: North Korean refugees. Accuracy in Oral History. Memory and Identity.

\section{RESUMEN RELATOS DE REFUGIADOS NORCOREANOS: HISTORIA ORAL E NARRATIVAS AUTOBIOGRÁFICAS}

Las entrevistas y relatos autobiograficos de refugiados norcoreanos, divulgados en fuentes mediáticas o en libros, serán la base para la discusión que se hace en este artículo que retomará el debate sobre precisión en las narrativas de historia oral. El caso de Yeonmi Park será uno de los ejemplos abordados. ¿Las fallas en la memoria indicarian que un narrador es mentiroso? Como los investigadores de historia oral deben lidar con las inconsistencias de las narrativas con las cuales trabajan? El texto abordará las narrativas en la construcción de una identidad colectiva del desplazamiento y también como un recurso de la historia pública. Se harán reflexiones sobre los recursos que la historia oral dispone para trabajar con las imprecisiones en los testimonios.

Palabras clave: Refugiados norcoreanos. Verdad en Historia Oral. Memoria e Identidad.

Este artigo analisará um conjunto de relatos autobiográficos de refugiados norte-coreanos, divulgados em fontes midiáticas e livros, tendo por base o debate, tão frequente na literatura da área, sobre a precisão dos relatos da história oral. O caminho do texto mostrará que, para além das inexatidões, as narrativas revelam uma tentativa de afirmação da identidade do exílio. A história de Yeonmi Park será o ponto de partida da discussão, analisada ao lado de três outros casos: Eunsum Kim, Thae Yong-ho e Shin Dong-Hyuk. O trabalho baseiase em um acervo de testemunhos de norte-coreanos, coletados pela autora deste texto, ao longo de quase dez anos, todos obtidos em fontes secundárias. Serão analisadas histórias de fuga e, a partir delas, será apresentada uma reflexão sobre o seu papel na identidade desses narradores.

Além desta Introdução e das Considerações Finais, o texto está divididos em cinco partes: O trabalho com as fontes secundárias: os relatos de norte-coreanos, na qual é apresentada a metodologia empregada na presente análise; As narrativas de norte-coreanos que fugiram de seu país, que apresenta o contexto em que são produzidos os relatos dos norte-coreanos; Precisão e confiabilidade em história oral, item que retoma a discussão que outros autores fizeram sobre o tema da precisão em história oral, apresentando sua contribuição para este artigo; Testemunhos de refugiados norte-coreanos: o caso de Yeonmi Park descreve e discute as circunstâncias de produção do 
relato de Yeonmi e os temas que ele suscita; e o que os relatos de norte-coreanos têm a dizer sobre seus narradores analisa o discurso de Yeonmi, em conjunto com os relatos de outros fugitivos.

\section{O trabalho com as fontes}

\section{secundárias: os relatos de norte-} coreanos

A fonte principal que compõe a presente análise são os relatos de refugiados norte-coreanos disponiveis em fontes secundárias, divulgados tanto em livros, quanto em websites da internet dedicados ao tema da Coreia do Norte.?

A quantidade de narrativas disponiveis nessas fontes é gigantesca, por isso a autora selecionou algumas delas para comporem seu acervo de pesquisa. Para este texto, foram escolhidos relatos segundo os seguintes critérios: 1) estarem disponiveis em português ou inglês; 2) em se tratando de livros, foram escolhidos aqueles que a autora deste artigo conseguiu encontrar para comprar no Brasil ou que puderam ser adquiridos em viagens ao exterior, estando agora em sua biblioteca pessoal; 3) para o processo de escolha de histórias disponiveis em websites, foram separadas aquelas que estivessem disponiveis em páginas em português ou inglês e, como a quantidade é imensa, ficou estabelecido que seriam selecionados apenas três relatos para este artigo, além do de Yeonmi, dentre os inúmeros do acervo que foi constituído durante a análise do material. Esses relatos foram buscados em websites especializados em temas da Coreia do Norte e também em outros voltados à postagem de vídeos na rede.

Foram encontradas centenas de narrativas, de modo que foi preciso sortear algumas que

1 Disponiveis em: <www.youtube.com>. (Youtube); <https://www.libertyinnorthkorea.org/>. (Liberty in North Korea); e <https://www.eahrnk.org/>. (European Alliance for Human Rights in North Korea). Acesso em: 06 mar. 2018. compusessem este trabalho, que não contou com financiamento ou com estagiários para o processo de seleção e depuração dos dados. Dessa forma, um número limitado de histórias precisou ser estabelecido.

Após a seleção das histórias que entrariam na análise, procedeu-se à leitura/escuta cuidadosa de cada narrativa. Decidiu-se, então, que alguns critérios temáticos orientariam esse processo, entre eles: o percurso pelo qual o refugiado descrevia sua vida e a saída da Coreia do Norte; motivos apresentados para o escape; descrição das dificuldades enfrentadas no país de origem, bem como de seus pontos positivos; descrição sobre a violência e a violação de direitos humanos; forma de fuga e sua trajetória; chegada à China e percurso até a Coreia do Sul (quando foi o caso); entre outros assuntos, mas nem todos esses aspectos puderam compor o escopo deste artigo. A exemplo de Demartini (2005), optou-se por trabalhar com trechos dos relatos (fichamentos temáticos), pois a extensão e a variedade dos assuntos abordados pelos desertores eram muito ricas. Realizou-se o fichamento dos temas que apareciam nas histórias, como proposto por Demartini (2005), por meio de marcadores temáticos que orientaram a separação e o agrupamento de trechos, conforme o assunto era abordado pelo narrador.

Foi a partir dessa análise temática - e do seu confronto com o artigo da jornalista Mary Ann Jolley (2014) - que a discussão sobre verdade narrativa se construiu. A busca por elementos constituintes da identidade desses refugiados, presentes nos seus discursos, também foi parte importante do entendimento do processo de construção da sua memória coletiva.

A proposta do artigo é trabalhar apenas com as fontes orais secundárias, ainda que outros dados documentais sejam eventualmente citados, ao longo da análise. 
As narrativas de norte-coreanos

\section{que fugiram de seu país}

Refugiados da Coreia do Norte têm produzido um importante e variado acervo de autobiografias e entrevistas, disponiveis em formatos diversos, incluindo desde vídeos de internet até documentários e livros, entre outros meios.

É necessário esclarecer, logo de início, que este artigo recorrerá a três termos diferentes para designar o status dos narradores nortecoreanos: desertores, fugitivos e refugiados. A esse respeito, cabem algumas observações: "deserção" poderia erroneamente sugerir a ideia de abandono de um dever para com a pátria, como se eles fossem traidores, julgamento que não é compartilhado pela autora deste texto. Recorreremos eventualmente a essa palavra por ser amplamente veiculada em artigos acadêmicos de língua inglesa, definindo o abandono da terra de origem quando em desacordo com o regime vigente, mas não no sentido de traição. O conceito de refúgio é usado pelas organizações de direitos humanos que atuam na região, mas não é assim que tem sido reconhecido pelos países asiáticos vizinhos da Coreia do Norte para onde se dirigem esses norte-coreanos. Refúgio, para a Organização das Nações Unidas e para as organizações não governamentais, indica a situação de pessoas que fogem de conflitos e perseguições, sendo forçadas a cruzar fronteiras para garantir sua segurança e sobrevivência. Por fugitivos, podemos definir as pessoas que estão literalmente escapando de uma realidade abusiva. Ainda que essas expressões possam ser alvo de disputas políticas e identitárias, acionaremos as três, durante este texto, para fazermos referência às diversas possibilidades que aparecem na bibliografia aqui mobilizada e para refletirmos sobre a identidade que emerge das narrativas. Entendemos que o status desses norte-coreanos é ambíguo, polêmico, e que carrega um pouco dos três sentidos, podendo ser desertores, quando cruzam a fronteira por motivos de discordância política; devendo ser considerados refugiados pelos países vizinhos (mas não o são, como veremos); e fugitivos, por saírem ilegalmente de seu país "na calada da noite". Preferiremos, entretanto, o termo "refugiado", pelo seu sentido político de luta pela proteção que thes é negada nos países de fronteira.

As histórias de refugiados norte-coreanos têm suscitado curiosidade e polêmica, por parte da mídia e do público, em torno de sua veracidade e acuidade. As desconfianças são alimentadas pela dificuldade de acesso à Coreia do Norte e por interesses políticos sobre as causas e efeitos das deserções (são defensores do regime que questionam a verdade das histórias supostamente contadas por "traidores" - e, por outro lado, seus opositores, que veriam nelas a confirmação de suspeitas sobre as mazelas do socialismo). ${ }^{2}$ Todavia, pouco se sabe do que acontece na terra de Kim Jon-un, a não ser por meio do que tem sido contado por esses fugitivos ou por visitantes esporádicos que têm acesso limitado ao cotidiano do país.

Os questionamentos sobre a verdade dessas histórias acabam, contudo, por desprezar certo conteúdo subjetivo de sofrimento e de superação das adversidades construído a partir de experiências comuns a inúmeros refugiados norte-coreanos. Em que pesem os interesses políticos, conviria sublinhar que a verdade dos relatos importa menos à história oral do que aquilo que eles revelam sobre a construção de uma memória coletiva ${ }^{3}$ dos desertores

2 Este artigo não pretende defender ou criticar o regime político da Coreia do Norte. O objetivo é precisamente analisar os relatos de refugiados dentro de seu próprio contexto narrativo.

3 Sobre o conceito de memória coletiva, ver, entre outros, Halbwachs (2006) e Bosi (1993). A noção de memória coletiva, entre outras coisas, implica que as lembranças, muito além de serem individuais, são compartilhadas e mantidas pelo grupo social e, com ele, definem processos identitários. Desse modo, a memória coletiva é um importante recurso conceitual para entendermos a ponte entre as dimensões da 
e daquilo que elas mostram sobre a construção de sua identidade no exílio. A importância dos testemunhos residiria justamente no compartilhamento de experiências e na afirmação de sua identidade de expatriação, em resposta à recusa dos países vizinhos em reconhecê-los como refugiados.

A saída de norte-coreanos do seu país, a partir de meados dos anos de 1990, mudou de perfil, passando de fuga em busca de liberdade, por dissidentes do regime, para se tornar migração de refúgio ambiental ou econômico, ocasionada pela Grande Fome ou por desastres naturais (GAHNG, 2010; SONG, 2015a).

No período entre os anos de 1995 até 1998, com o advento da chamada Grande Fome ou Marcha Dolorosa, ${ }^{4}$ houve um aumento de nortecoreanos cruzando a fronteira com a China, segundo Gahng (2010). A autora afirmou que as estatísticas de 2005 teriam estimado dois milhões de norte-coreanos vivendo em território chinês.

Na questão dos refugiados norte-coreanos, a política chinesa tem dificultado a passagem por sua fronteira e tem frequentemente recorrido à sua deportação. Por outro lado, órgãos internacionais - preocupados com o tratamento dado pela Coreia do Norte aos desertores - têm pressionado o governo chinês para que ofereça proteção a esses sujeitos. Para a China, porém, eles seriam apenas migrantes econômicos (e não refugiados), não precisando, portanto, de proteção; desse ponto de vista, se caracterizariam para eles simplesmente como estrangeiros ilegais.

O mesmo acontece em outros países sul-asiáticos - como Camboja, Indonésia e Filipinas

subjetividade e da coletividade, e sobre como essas duas dimensões dialogam e se relacionam dialeticamente.

4 As expressões Grande Fome ou Marcha Dolorosa referem-se ao período entre 1995 e 1998, quando a Coreia do Norte, então isolada pela Queda do Muro de Berlim e pelo final do comunismo nos países aliados, sofreu perdas na agricultura e com desastres naturais. Estima-se que até um milhão de pessoas tenham morrido de fome.
- por onde os norte-coreanos passam quando conseguem sair da China em direção à Coreia do Sul (por meio de contrabandistas de pessoas). Nesses territórios, por razões estratégicas e de relações diplomáticas com a $\mathrm{RPCN},{ }^{5}$ os fugitivos também não são considerados refugiados. E, finalmente, quando chegam à Coreia do Sul, continuam não sendo vistos como refugiados, mas sim como cidadãos coreanos, já que a Coreia do Sul não reconhece a do Norte como um país separado e sim como parte de uma só nação em estado de guerra (que foi suspensa pelo Armistício de 1953, ainda em vigor).

Vê-se, portanto, que há disputas em relação à identidade dessas pessoas, conforme interesses políticos e econômicos. É nesse cenário que transitam as narrativas dos desertores. Do ponto de vista de quem conta as histórias, elas seriam um recurso de afirmação de sua identidade como vitimas do regime de Pyongyang e do contexto político da região (e não da identidade de migrantes ilegais), enquadrando-se, portanto, na categoria de "refugiados". Os relatos autobiográficos refletem também o protagonismo desses fugitivos em denúncias de violação dos direitos humanos e na construção de sua história pública.

No complexo contexto identitário desses refugiados, os pesquisadores de história oral foram agraciados com um disparador do debate proporcionado pelo texto da jornalista australiana Mary Ann Jolley (2014), que desmentia o depoimento da norte-coreana Yeonmi Park proferido na One World Summit, de 2014. ${ }^{6}$ Partindo desse episódio, várias questões clássicas da história oral poderiam ser retomadas: seriam as falhas na memória indicativas de que um narrador é mentiroso? Como os pesquisadores de história oral devem lidar com as inconsistências dos relatos com os quais tra-

5 República Popular da Coreia do Norte.

6 Yeonmi Park. One Young World Summit, 2014. Disponível em: <https://youtu.be/Ei-gGvLWOZI>. Acesso em: 21 nov. 2017. 
balham? Julgar verdades e mentiras seria um dos papéis do historiador oral?

No presente artigo, que parte do episódio do texto de Ann Jolley (2014) como um disparador de debate, as imprecisões de algumas das autobiografias citadas nos permitirão entender a construção de uma narrativa única e coesa sobre a experiência de deixar a Coreia do Norte - e da nova vida fora dela -, além da afirmação de uma memória coletiva do país de origem e da fuga como bases para a formação da identidade no exílio e na reivindicação do status de refúgio.

0 pressuposto do qual partiremos é de que a memória evocada nessas narrativas é construção e que as histórias dos refugiados norte-coreanos são expressões simbólicas desse processo construtivo, que muito tem de social e de subjetivo. Para Alessandro Portelli, “a primeira coisa que torna a história oral diferente é aquela que nos conta menos sobre os eventos e mais sobre os significados. Isso não implica que a história oral não tenha validade factual" (PORTELLI, 1997, p. 31). A simples validade factual seria resolvida facilmente com a verificação em outras fontes, mas é a atenção à subjetividade do narrador e às suas relações com a coletividade que singulariza o trabalho com fontes orais.

A esse respeito, Ecleá Bosi (2003, p. 62) atestou que "recordar é sempre um ato de criação", de modo que o narrado e o real são instâncias diferentes - intermediadas pela memória -, mas também complementares. As lembranças têm muito a dizer sobre a história e a identidade de um grupo. Então, o que interessaria à história oral não seria a correspondência exata entre fatos vividos e fatos contados, mas sim o processo de construção simbólica da história e sua relação com a memória coletiva.

Isso não quer dizer, contudo, que não seja importante trabalharmos com fontes diversas (complementares às orais), e por vezes confli- tantes, em nossa prática de pesquisa. A diversidade de discursos e de visões sobre os acontecimentos interessa à história oral, não no sentido do confronto, mas sim do entendimento da pluralidade de linguagens, percepções e interesses históricos sobre um mesmo fato e da percepção da multiplicidade de discursos sobre a História.

\section{Precisão e confiabilidade em história oral}

Foi a partir do final dos anos de 1970, especialmente com os estudos de Alessandro Portelli (1979) sobre a classe trabalhadora da periferia de Roma, que os temas da memória e da subjetividade foram introduzidos na história oral. Para a visão tradicional da História, a validade dos relatos como documentos esteve sempre atrelada à sua confiabilidade.

Segundo Alistair Thomson (1997), os primeiros manuais de história oral que surgiram após a retomada desse campo, nos anos de 1970, estavam preocupados em estabelecer critérios para avaliar a confiabilidade da fonte oral. Mas essa preocupação em mostrar como os acontecimentos se deram de fato acabou por deixar de lado, segundo ele, outros valores do testemunho e também os significados subjetivos das lembranças.

A obsessiva atenção à confiabilidade das fontes orais foi se transformando, no final dos anos de 1980, na Grã Bretanha, na Austrália (THOMSON, 1997) e também no Brasil, em um investimento na relação entre relato e subjetividade e entre lembrança e identidade:

Procuramos explorar a relação entre reminiscências pessoais e memória coletiva, entre memória e identidade e entre entrevistador e entrevistado. Na verdade, geralmente estamos tão interessados na natureza e nos processos de afloramento de lembranças quanto no conteúdo das reminiscências que registramos, e a relação entre as imagens e o conteúdo das reminiscências tornou-se de extrema impor- 
tância na análise e no uso do testemunho oral. (THOMSON, 1997, p. 54)

Os estudos de memória contribuíram para essa nova orientação, mostrando que os fatos contados na entrevista de história oral são um produto da subjetividade e que, portanto, as condições de construção das narrativas seriam analiticamente mais relevantes do que a sua precisão factual.

Luisa Passerini (2011) mostrou que as imprecisões não deveriam ser tomadas como motivo para o descrédito das fontes orais, mas sim o contrário: deveriam ser vistas não como erros factuais, mas como testemunhos de mudanças na percepção dos fatos, ao longo do tempo.

As fontes orais devem interessar ao pesquisador não pelo que podem revelar sobre a verdade dos fatos, mas sim pelo que expõem sobre a percepção dos homens sobre os fatos. Elas são, segundo Portelli (1997, p. 32):

[...] aceitáveis, mas com uma credibilidade diferente. A importância do testemunho oral pode se situar não em sua aderência ao fato, mas de preferência em seu afastamento dele, como imaginação, simbolismo e desejo de emergir. Por isso não há 'falsas' fontes orais. Uma vez que tenhamos checado a sua credibilidade factual com todos os critérios estabelecidos do criticismo filológico e verificação factual, que são requeridos em qualquer tipo de fonte em qualquer circunstância, a diversidade da história oral consiste no fato de que afirmativas 'erradas' são ainda psicologicamente 'corretas' e que essa verdade pode ser igualmente tão importante quanto registros factuais confiáveis.

A esse respeito, Janaína Amado (1995) também indicou que a dimensão simbólica das narrativas orais faz parte da História e por isso não pode ser negligenciada pelo pesquisador. É essa lógica simbólica que deve ser procurada no processo de análise histórica e sociológica, pois memória e imaginação andam juntas:

Parece-me necessário, antes de tudo, distinguir entre o vivido e o recordado, entre expe- riência e memória, entre o que se passou e o que se recorda daquilo que se passou. Embora relacionadas entre si, vivência e memória possuem naturezas distintas, devendo, assim, ser conceituadas, analisadas e trabalhadas como categorias diferentes, dotadas de especificidade. $O$ vivido remete à ação, a concretude, às experiências de um indivíduo ou grupo social. $\mathrm{A}$ prática constitui o substrato da memória; esta, por meio de mecanismos variados, seleciona e reelabora componentes da experiência. A Revolta do Formoso foi uma coisa; outra, diferente, foram as memórias que Fernandes construiu a respeito da revolta.

História e memória, entretanto, mantêm tantas relações entre si, que é até difícil pensá-las separadamente [...]. (AMADO, 1995, p. 131)

A autora salientou ainda que toda narrativa é sempre um ponto de vista sobre os fatos:

Toda narrativa apresenta uma versão, um ponto de vista, sobre algo. A narrativa de Fernandes constituiu uma versão, entre muitas, da Revolta do Formoso; até hoje ela disputa, com outras, espaços, audiências e adesões, em busca de legitimidade social e histórica. 'Importa a versão, não o fato': o antigo ditado popular já chamava a atenção para a importância e autonomia das interpretações. Toda narrativa articula alguns elementos, como: quem narra, o quê narra, por que narra, como narra, para quem narra, quando narra [...] As formas - quase infinitas - de articulação entre esses elementos resultam do uso de códigos culturais (linguagem, estilo, gênero literário etc.) à disposição dos autores, em determinada época, e, também, da contribuição individual oferecida por cada autor, ao escolher os códigos que utilizará em sua narrativa, e os modos como o fará. 0 uso desse espaço individual de criação varia, de autor para autor: alguns inventam códigos inteiramente novos; outros tendem a utilizar-se dos já existentes (HARLAN, 1989). Toda narrativa, no entanto, possui uma dose, maior ou menor, de criação, invenção, fabulação, isto é: uma dose de ficção. (AMADO, 1995, p. 133-134)

Além da dimensão simbólica das lembranças e de sua característica criativa, vale ressaltar também que o historiador oral, diferen- 
temente dos pesquisadores da área médica, não lida com a memória no seu sentido clínico (ou seja, como um registro fisiológico neutro das lembranças nos neurônios), mas sim com algo que é vivo e que flui como um rio (KOTRE, 1997). A memória autobiográfica, segundo Kotre (1997), tem a capacidade de revisar a si mesma, ao longo da vida. É o presente que é revelado por ela, não o passado.

A exatidão das lembranças também não garante a veracidade dos fatos lembrados (KOTRE, 1997) e os motivos para isso são vários: a memória sofre diversas interferências (do tempo da lembrança, das emoções, da presença de interlocutores e de outras situações, como objetos ou sons); as lembranças podem ser criadas; e até porque o próprio cérebro é maleável, ele muda ao longo da vida. Podemos, porém, confiar na nossa memória (autobiográfica) porque ela nos fornece um "amparo ancestral" para continuarmos a viver, nos dá um ancestral mitológico que justifica nossas ações e que nos ajuda na compreensão da razão de nossa existência (KOTRE, 2013).

Entender a confiabilidade das histórias a partir de seu contexto de memória não significa, no entanto, que não haja fatos a serem conhecidos. Cabe ao pesquisador entender as incoerências das histórias como construções sobre a realidade (o que não quer dizer, por outro lado, que estejamos afirmando a verdade dessas incoerências). Técnicas de análise que combinam diferentes versões narrativas a outros documentos complementares nos ajudam a realizar esse trabalho, não no sentido do confronto entre fontes, mas do entendimento das diversas interpretações sobre um mesmo acontecimento.

A esse respeito, em uma crítica a intelectuais que assumem a validade absoluta de toda e qualquer narrativa, Patai (2013) argumentou que interesses políticos podem interferir na defesa de certos discursos orais incoerentes.
A autora analisou o caso da militante indígena guatemalteca Rigoberta Menchú, ganhadora do Nobel da Paz, cujo relato foi desmentido pelo antropólogo americano David Stroll (1993 apud PATAI, 2013). Com as inconsistências nas partes mais importantes da sua história, Menchu ofuscou justamente as vozes de outros guatemaltecos, que reivindicou representar, mas que não se viam representados por ela:

A pesquisa e as entrevistas conduzidas por Stoll, além disso, demonstraram que muitos dos vizinhos de Menchú sentiam-se bastante divididos a respeito das guerrilhas, com muitos deles desertando para o lado do exército assim que percebiam que as guerrilhas não os protegeriam. Essa não é uma questão insignificante, já que muito do prestígio de Menchú era oriundo da reivindicação de estar falando em nome de um povo inteiro, afirmação constantemente repetida por seus admiradores. (PATAI, 2013, p. 171)

O trabalho de Stroll (1993 apud PATAI, 2013) ocasionou grande controvérsia, de modo que defensores de Rigoberta passaram a questionar a credibilidade do pesquisador, invertendo as críticas que ele havia feito ao depoimento de Menchú. Segundo Patai (2013), os intelectuais que puseram em dúvida a seriedade do trabalho de Stroll (1993 apud PATAI, 2013) o fizeram porque abarcaram uma retórica pósmodernista de que o mundo real se reduziria apenas ao discurso, assim, eles teriam se desapegado do real para defenderem suas crenças. Para ela, as discussões não levantavam problemas, mas sim ataques pessoais:

Parece óbvio que testemonios como de o de Rigoberta fazem mais do que nos apresentar narrativas fascinantes, subjetivas, embora isso seja certamente um de seus principais atrativos e forças. Esses textos também fazem afirmações sobre as vidas de seus sujeitos e sobre as sociedades nas quais elas são vividas. Eles seriam privados de significado político se falhasse nisso. Porém, os pesquisadores deveriam se comprometer com um tipo de trabalho bem 
diferente. Suas paixões políticas não deveriam eclipsar as exigências de pesquisa séria nem as reações refletidas a respeito da interpretação de eventos complexos. [...] Embora pesquisadores, individualmente, possam ter compromissos com a política, seus posicionamentos políticos não garantem nem qualidade, nem exatidão, nem relevância às suas pesquisas. Pelo contrário, conforme a política muda, fica claro que os trabalhos subordinados a demandas e compromissos políticos serão colocados sob rigoroso escrutínio - como deve de fato acontecer. (PATAI, 2013, p. 181-182)

Nesse sentido, e a fim de evitar compromissos políticos que possam por a perder o trabalho analítico, Patai poderia dizer que o pesquisador em história oral deve estar preparado para entender os processos que conduzem à construção de um relato específico, mas dentro de seu universo simbólico e da moldura da memória coletiva, evitando fazer uma apropriação política desses significados para não ofuscar a relação entre construção narrativa e História.

Essa compreensão de que o trabalho com história oral deve buscar as dimensões simbólicas da construção da memória coletiva nos guiará pela análise dos relatos de refugiados norte-coreanos. Chegamos, portanto, às questões políticas e simbólicas que a discussão sobre a acuidade do relato do testemunho de Yeonmi Park nos propõe.

\section{Testemunhos de refugiados}

norte-coreanos: o caso de Yeonmi Park

Em 18 de outubro de 2014, em Dublin, Yeonmi Park, uma refugiada norte-coreana de 21 anos, proferiu um depoimento na One Young World Summit ${ }^{7}$ que chocou ouvintes do mundo inteiro. Em seu testemunho emocionado, com

7 Yeonmi Park. One Young World Summit, 2014. Disponível em: <https://youtu.be/Ei-gGvLWOZI>. Acesso em: 24 abr. 2017. duração aproximada de oito minutos, Yeonmi descreveu a fome e as perseguições vividas por ela e por sua família na província de Hyesan, na Coreia do Norte.

Entre outras coisas, ela falou da dificil travessia enfrentada pelos fugitivos no rio Yalu, que divide China e Coreia. Yeonmi descreveu também a situação dos refugiados que caem nas mãos de traficantes chineses (os únicos que conseguem propiciar essa fuga, porque os norte-coreanos são ilegais na China, podendo ser devolvidos ao seu país, caso sejam pegos). Tomada pela comoção, Yeonmi contou que viu sua mãe ser estuprada por um atravessador, quando chegaram à margem chinesa do rio. Ela relatou os anos que viveu ilegalmente na China até que conseguissem atravessar o deserto da Mongólia para pedirem asilo na Coreia do Sul. Sua saga se tornou objeto de um livro que foi traduzido no Brasil como Para pode viver, publicado em 2016.

Nessa obra de 2016, Yeonmi detalhou toda a sua jornada: a vida na Coreia do Norte, a fuga para a China e a chegada à Coreia do Sul. As lembranças que estão no livro são muito precisas, especialmente aquelas da infância remota, o que pode suscitar dúvidas sobre a acuidade da história por causa da sua pouca idade quando os eventos ocorreram. 0 texto retratou também o deslumbramento inicial de Yeonmi com a comida, os hábitos e os produtos chineses, tão diferentes da escassez da Coreia do Norte. Além disso, foram descritas as redes de tráfico de noivas norte-coreanas, suas hierarquias e as cadeias de atravessadores que começam na RPCN e têm sua ponta final no comprador chinês.

Yeonmi nasceu em 1993, na cidade nortecoreana de Hyesan, na fronteira com a China, às margens do rio Yalu. Seu pai tem origem em uma família de classe privilegiada de militares, com boas relações políticas, mas que perdeu seu status após um parente ter sido acusado 
de criminoso. 0 pai trabalhava em uma fábrica, mas sustentava a família com o comércio ilegal de produtos contrabandeados da República Chinesa. Nos anos de prosperidade, a família viveu bem, até que ele foi descoberto e preso, deixando todos em situação precária. Yeonmi fugiu da Coreia do Norte, em 2006, aos 13 anos, e hoje vive nos Estados Unidos, sendo uma ativista dos direitos humanos. Ela se dedica a denunciar a situação dos fugitivos do regime.

A época da Grande Fome foi lembrada em seu livro como um evento que teve impacto na sua decisão de fugir, ainda que Yeonmi e sua família tenham desertado bem depois disso. Nos anos 2000, a miséria dos anos 1990 havia diminuído, mas a maior parte da população da Coreia do Norte ainda não podia se alimentar bem. Os tempos seguintes à prisão de seu pai foram de penúria e de privação para toda a família.

Ela também contou diversos outros episódios de sua vida na Coreia do Norte como, por exemplo, quando tinha oito anos e seu pai foi preso por contrabando. Em seguida, sua mãe ficou mais de um mês fora da Hyesan, para conseguir comida, deixando as duas filhas sozinhas com um saco de arroz para todo o período.

Por causa da situação precária da família, que já se estendia há anos, sua irmã conseguiu cruzar a fronteira com a China, em busca de melhores condições de vida, em 2006. Em seguida, Yeonmi e sua mãe decidiram ir atrás para procurá-la. A trajetória de sua fuga da Coreia do Norte até a chegada em Seul foi longa e narrada, de maneira heroica e dramática, no livro.

Logo após a travessia pelo rio Yalu, na fronteira entre os dois países, sua mãe foi vendida como esposa de um chinês, na casa dos trinta anos, que vivia em uma fazenda no interior remoto da China, onde há um mercado ilegal de noivas-escravas norte-coreanas, especialmente alimentado por homens com pouca chan- ce de conseguirem um casamento, tais como deficientes e agricultores de regiões de difícil acesso.

Por ter apenas 13 anos, Yeonmi ficou aos cuidados de um terceiro traficante da cadeia de atravessadores que fizeram parte de sua travessia pela fronteira. Ao longo dos anos, ela se tornou uma espécie de funcionária dos negócios ilícitos desse atravessador e eles acabaram por se relacionar em concubinato, que era a única opção de sobrevivência que ela tinha. Foi ele que conseguiu retirar seu pai da RPCN, quando já estava muito debilitado de câncer, e que comprou novamente sua mãe das mãos do marido chinês. Seu pai morreu em 2009, na China e, segundo ela, foi preciso enterrá-lo às escondidas para não ser pega pela polícia chinesa.

Depois de anos vivendo com esse amante/protetor, Yeonmi e sua mãe conseguiram ir embora para a cidade chinesa de Shenya$\mathrm{ng}$, contando inclusive com a ajuda dele, onde trabalharam em atividades eróticas de vídeochat. Foi isso que permitiu a elas o sustento e o dinheiro para fugirem da China. Nessa cidade, souberam de redes de missionários que conseguiam levar refugiados norte-coreanos pelo Deserto de Gobi, na Mongólia, até chegarem à Coreia do Sul. A viagem de fuga durou quatro dias, em condições árduas de frio, estresse e medo.

Ao chegarem à Coreia do Sul, passaram três meses em um centro de adaptação que dá orientações básicas para a vida no capitalismo como, por exemplo, dicas para usar um banco ou a internet. Em 2013, ela e sua mãe finalmente reencontraram a irmã mais velha, Eunmi, que estava desaparecida desde que fugiu da Coreia do Norte.

O final do livro é dedicado às dificuldades que os norte-coreanos enfrentam na Coreia do Sul, em relação à adaptação cultural, à vida no capitalismo e à realidade como cidadãos de 
segunda classe, os chamados talbukja, que é como essas pessoas se sentem ao chegar em seu tão sonhado destino final.

No artigo The Strange Tale of Yeonmi Park (2014), a australiana Ann Mary Jolley apontou inúmeras incoerências na história contada por Yeonmi, no discurso na One Young Word Summit (PARK, 2014), que reverberaram em blogs e por toda a internet (seu texto inclui, ao final, a resposta da norte-coreana aos questionamentos por ela apresentados).

A jornalista detectou essas imprecisões, a partir do discurso que Yeonmi fez na One Young Word Summit e em entrevista que ela the concedeu. Dentre os problemas apontados, um deles foi a "qualificação" da narradora: Yeonmi seria uma celebridade de programa televisivo para refugiados norte-coreanos na Coreia do Sul e estaria preocupada em atrair atenção. Outros impasses também foram citados: a refugiada havia nascido em 1993, mas o período da Grande Fome, frequentemente citado por ela, havia acontecido em meados dos anos 1990, quando seria ainda muito jovem para dele se lembrar; Yeonmi mencionou ter presenciado uma execução pública na infância, mas segundo Jolley, outros refugiados garantiram que as execuções aconteciam somente em locais afastados e até o ano de 1999. Dentre outras supostas inconsistências estão, por exemplo, o tempo em que seu pai ficou preso, a topografia de Hyesan (teria montanhas ou não?), a cremação secreta ou não do corpo do pai na China etc. Analisaremos, neste artigo, as lembranças sobre execuções e sobre a fome.

Jolley também confrontou o relato de Yeonmi com o da mãe dela e detectou certas incompatibilidades. A mãe havia dado a entender que a filha teria tomado mais consciência da situação da Coreia do Norte, só depois de ter começado a trabalhar em programas de TV na Coreia do Sul, de modo que esse contato poderia ter moldado o conteúdo de sua narrativa.

Na resposta que Yeonmi publicou, disponivel ao final do artigo de Jolley (2014), algumas explicações foram apresentadas para as alegações de incoerência. Por exemplo, o fato dela ser muito jovem quando os eventos aconteceram; a sua pouca fluência na língua inglesa, quando proferiu seus primeiros discursos e entrevistas; e o medo de que, ao fornecer detalhes precisos e verdadeiros sobre sua jornada, ela e sua família pudessem sofrer perseguições e represálias. Esse medo foi deixado de lado, quando publicou sua história em livro.

Sobre as execuções públicas, a jornalista encontrou alguns problemas no discurso de Yeonmi. Primeiramente, em relação ao local da execução, que ela disse ter presenciado, supostamente no estádio de Hyesan:

Quando Park tinha nove anos, aproximadamente em 2002, ela disse ter visto a melhor amiga de sua mãe ser executada no estádio de Hyesan. Mas, de acordo com vários fugitivos que não querem se identificar por medo de represálias, as execuções públicas somente aconteciam nos arredores da cidade, a maioria no aeroporto, nunca em estádios ou ruas e não houve nenhuma após o ano 2000 - dizem que o último foi uma execução em massa de 10 ou 11 pessoas, em 1999. (JOLLEY, 2014, on-line, Tradução nossa) ${ }^{8}$

Ou seja, segundo Ann Jolley (2014), o relato de Yeonmi sobre as execuções em locais públicos não coincidiria com os testemunhos de outros norte-coreanos que entrevistou.

A esse respeito, Yeonmi respondeu o seguinte, no próprio artigo de Jolley:

8 No original: "When Park was nine, which would have been around 2002, she says she saw her best friend's mother executed at a stadium in Hyesan. But, according to several North Korean defectors from Hyesan who didn't want to be identified for fear of reprisal, public executions only ever took place on the outskirts of the city, mostly at the airport, never in the stadium or streets, and there were none after 2000 - the last they recall was a mass execution of ten or eleven people in 1999". 
Na maior parte do tempo, as confusões se deveram à minha dificuldade com a língua. Eu só comecei a aprender inglês no último ano e estou tentando melhorar minha fluência para representar melhor o meu povo. Peço desculpas por qualquer mal-entendido. Por exemplo, eu nunca disse que vi execuções públicas em Hyesan. A amiga da minha mãe foi executada em uma pequena cidade da Coréia do Norte central (que eu não quero nomear), onde minha mãe ainda tem parentes. Eu também peço desculpas porque houve momentos em que as minhas memórias de infância não foram perfeitas, como sobre o tempo que meu pai passou na prisão. Estou checando agora com minha mãe e outras pessoas para corrigir tudo. (Resposta de YEONMI a JOLLEY, disponível no próprio artigo de JOLLEY, 2014, on-line, Tradução nossa) ${ }^{9}$

Segundo Yeonmi, em pedido de desculpas pelas inconsistências encontradas, as dificuldades com o inglês e a pouca idade, quando os eventos aconteceram, explicariam as imprecisões. Ela assumiu também que suas lembranças de infância poderiam não ser exatas e se comprometeu a checar tudo para escrever seu livro.

As críticas de Jolley (2014) foram feitas logo após o discurso de Yeonmi na One Young World Summit e provavelmente fizeram com que ela tomasse mais cuidado com as incoerências, ao escrever seu livro, no qual as execuções públicas já apareciam modificadas:

Na Coréia do Norte, as execuções públicas eram usadas para nos ensinar lições de lealdade ao regime e quais as consequências da desobediência. Em Hyesan, quando eu era pequena, um jovem foi executado logo atrás do mercado

9 No original: "Much of the time, there was miscommunication because of a language barrier. I have only learned English in the last year or so, and I'm trying hard to improve every day to be a better advocate for my people. I apologize for any misunderstandings. For example, I never said that I saw executions in Hyesan. My friends' mother was executed in a small city in central North Korea where my mother still has relatives (which is why I don't want to name it). [...] Also, I apologize that there have been times when my childhood memories were not perfect, like how long my father was sentenced to prison. Now I am checking with my mom and others to correct everything". por ter matado e comido uma vaca. Era crime comer carne bovina sem permissão. [...] 0 jovem havia cometido outros pequenos crimes, mas matar a vaca foi a transgressão principal. Ele sofria de tuberculose e não tinha nada para comer, mas para a polícia isso não fazia nenhuma diferença. Anunciaram sua execução à cidade inteira, e depois o trouxeram a uma pesada peça de madeira. Três homens com fuzis postaram-se à sua frente e começaram a atirar. Os executores tentavam cortar as cordas com as balas, e isso demorou muito tempo. Finalmente conseguiram, e o homem morto caiu frouxamente no chão. Minha mãe olhava a cena, chocada, enquanto eles rolavam o corpo e o enfiavam num saco para leva-lo embora na traseira de um caminhão. Seu sangue gelou, e por um momento ela não conseguiu mover as pernas. Não podia acreditar que em seu próprio país uma vida humana tivesse menos valor que a de um animal. Mesmo um cão seria tratado com mais respeito. (PARK, 2016, p. 67-68)

Neste trecho do livro, nota-se uma diferença na descrição da execução que teria presenciado, em relação à descrição que Jolley (2014) mencionou e criticou anteriormente à sua publicação. As lembranças de Yeonmi modificaram-se não só com a passagem do tempo, mas com a interferência da jornalista e também com a comparação com outras fontes, por exemplo, com as lembranças de sua mãe, como é comum que aconteça em processos mnemônicos.

Ainda que episódios variados sobre essas execuções tenham sido narrados, em diferentes momentos, por Yeonmi, parece que eles foram reforçados, na maior parte dos discursos que proferiu, e também em seu livro.

Especificamente sobre as imprecisões na história das execuções públicas, provavelmente há fatos que aconteceram e outros exagerados, em sua história, mas não se pode negar que a leitura de seu livro e do conteúdo dos vídeos de alguns refugiados norte-coreanos provoque desconfiança pelo exagero que vemos em muitos episódios. No caso dela, são várias as 
situações que soam amplificadas. Um exemplo seria a descrição que fez sobre seu sequestro por um gangster chinês chamado Huang. Muitos dos detalhes parecem fantasiosos, como as roupas e joias que ele lhe teria oferecido logo no segundo dia em que a conheceu e também dos guardas que vigiariam seu luxuoso apartamento enquanto ela estava presa (PARK, 2016, p. 201-203). Pode-se supor que um gangster não gastaria tanto dinheiro com uma nortecoreana que acabou de conhecer porque seria mais fácil e mais barato entrega-la à polícia chinesa, além disso, mantê-la presa só geraria problemas com a polícia; e também é de se estranhar não haver pedido de resgate envolvido. Tais circunstâncias inverossímeis, entretanto, dão certo toque original à narrativa e prendem a atenção do leitor, tornando o quadro da vida do narrador muito original.

Esse recurso narrativo do exagero encontra eco no caso descrito por Amado (1995), em O Grande Mentiroso, no qual o entrevistado Fernandes, ao descrever a Revolta do Formoso, recorreu a episódios de Dom Quixote de La Mancha, história profundamente arraigada nas tradições do interior de Goiás, desde o século XVIII, conforme a autora percebeu, posteriormente à gravação do depoimento. O livro de Miguel de Cervantes teria fornecido, segundo a pesquisadora, recursos simbólicos para que Fernandes pudesse trazer à tona lembranças sobre a revolta, profundamente arraigadas em sua memória.

O exagero, somado às imprecisões, levanta desconfianças, mas podemos refletir sobre as explicações para isso. Entre elas, a construção de uma narrativa heroica do eu. Para Song (2015a), diferentemente do que pensam a Coreia do Norte e os países pelos quais passam esses fugitivos durante sua viagem à Coreia do Sul (onde são considerados ilegais ou traidores), essas narrativas se caracterizam pelo tom heroico:
Eu me considero um herói que salvou muitas vidas. Eu não posso ser um bom cidadão e respeitador das leis quando essas leis são feitas por pessoas más. (Entrevista citada por SONG, 2015a, p. 406)

Além disso, a pesquisadora Jiyoung Song (2015b) apontou outros motivos para as inconsistências em histórias de fugitivos norte-coreanos: os pagamentos por entrevistas oferecidos por veículos jornalísticos, na China e na Coreia do Sul, que envolvem boa soma de dinheiro e privilegiam histórias mais vendáveis; a demanda por histórias que causem comoção popular; e o próprio comprometimento dos desertores com as organizações de direitos humanos, que têm necessidade de discursos fortes e emotivos, a fim de legitimarem a causa dos refugiados.

Desse modo, os exageros nos relatos de Yeonmi e de outros refugiados norte-coreanos têm origem na própria relação entre os países de destino, a mídia e os narradores, e também em elementos simbólicos da memória coletiva, embaralhados em lembranças confusas sobre o processo de escapar da Coreia do Norte, como veremos a seguir.

\section{O que os relatos de norte- coreanos têm a dizer sobre seus narradores?}

0 fato de estarmos trabalhando, neste artigo, com relatos autobiográficos e entrevistas de fonte secundária, que descrevem a realidade de um país hermético, nos impõe alguns limites para a análise do sentido simbólico dos exageros das histórias, mas, mesmo assim, é possivel aventarmos algumas pistas.

Primeiramente, Yeonmi, como a própria Jolley (2014) mostrou, tinha algum destaque na mídia sul coreana por meio de um programa de TV para norte-coreanos. Isto certamente fez com que ela tivesse recursos performáticos diferentes de outros refugiados (fato que deve ter 
tido impacto em sua maneira de narrar, que se tornou mais fantasiosa). A jornalista Tammy Kim (2016) disse, a esse respeito, que Yeonmi aprendeu a vender sua imagem para a cultura das celebridades dos direitos humanos internacionais:

Exatamente com seus pais vendiam seus metais no mercado negro de Pyongyang e Hyesan, Park tornou-se uma vendedora no mercado de celebridades e dos direitos humanos internacionais. É um negócio que ela domina com maestria, seja na televisão ou no mercado do mundo.10 (KIM, 2016, on-line, Tradução nossa)

O destaque de Yeonmi na mídia televisiva deve ter moldado, de certa maneira, sua forma de narrar, propiciando relatos mais exagerados e fantasiosos e provavelmente interagindo com suas lembranças. $O$ efeito interessante desse processo é que o engrandecimento dos episódios vividos foi fundamental para que jovens do mundo inteiro pudessem despertar seus olhos para a situação dos refugiados norte-coreanos, após seu discurso de 2014.

Um segundo aspecto que explicaria o tom fantasioso dessas histórias é que a Grande Fome na Coreia do Norte, ainda que tenha acontecido no começo dos anos 1990 (quando Yeonmi era criança e seus pais tinham uma boa condição de vida), teve forte efeito na memória coletiva dos refugiados, tendo contaminado inclusive as lembranças de quem não viveu naqueles dias. Desse modo, não é de se estranhar que Yeonmi (e outros refugiados que eram crianças nesse período) se lembre desse evento como se o tivesse vivido. Parece, entretanto, que a fome perdurou em muitos grupos sociais da RPCN, após a Grande Fome, mas em menor escala, o que fica claro nos relatos.

$E$, por fim, a violência das execuções e existente nos campos de prisioneiros, ainda que

10 No original: "Just as her parents plied their wares in the black markets of Pyongyang and Hyesan, Park has become a vendor in the marketplace of celebrity culture and international human rights. It's a trade she's intent on mastering-on television and the world stage". não tenha sido presenciada por todos os norte-coreanos, certamente fazia parte tanto da doutrinação do regime de Pyongyang, quanto do universo de assuntos dos cidadãos comuns, de modo que aqueles que não vivenciaram nenhuma dessas situações podiam fantasiar tê-las vivido e até mesmo conseguiam imaginar tê-las presenciado, tão fortes eram essas imagens na memória coletiva dos refugiados.

Tammy Kim (2016), no jornal The Nation, especulou sobre a possibilidade de que uma das tentativas de desqualificação do discurso de Yeonmi tenha vindo do próprio governo de Kin Jong-un, que teria criado dois vídeos falsos no Youtube, com o fim de desmentir alguns dos fatos narrados por ela. Tammy Kim (2016) também chamou a atenção para os interesses políticos de desqualificação desses relatos e de seus narradores: coreanos do sul ligados à esquerda e coreano-americanos estariam criticando as organizações dos direitos humanos - principais divulgadoras das histórias de refugiados - por estarem minando as tentativas de unificação das Coreias, ao darem atenção excessiva aos testemunhos, sem uma preocupação com sua acuidade.

Há, portanto, um jogo de disputas de memória operando por trás da confiabilidade desses relatos: por um lado, haveria a reivindicação da memória de sofrimentos e abusos feita pelos fugitivos, legitimando sua condição de refugiados, e pelas organizações de direitos humanos; e, por outro, uma distinta reivindicação memorialística, que reforçaria a ideia da imigração ilegal, sendo pleiteada por grupos institucionais e pelas nações que lidam com essa realidade nas fronteiras. Ambos os lados disputariam seu reconhecimento, por meio da legitimação da memória, no complexo contexto das relações geopolíticas asiáticas."11

11 Song (2013) discute como a identidade e os interesses de mulheres norte-coreanas são transformados e manipulados, em diferentes contextos: na RPCN, na Coreia do Sul, nos países sul-asiáticos ou na China. Sua identidade varia, podendo pular de mulheres contra- 
No caso das execuções, importaria menos à história oral entender se Yeonmi as viu acontecerem em praça pública ou se elas acontecem de fato nas periferias das cidades, mas sim entender os seus significados na memória coletiva dos refugiados, moldados por lembranças que são repetidas em inúmeras histórias contadas por eles.

Ainda assim, há alguma evidência sobre possivel acuidade nessas recordações, bastaria lembrarmos que, em julho de 2016, Kim Jong-un executou seu vice-primeiro-ministro, Kim Yong-jin, por ter dormido em uma reunião parlamentar, fato amplamente divulgado nas mídias de todo o mundo; e que, em 2013, o mesmo ditador executou seu tio Jang Songthaek por supostos crimes contra a economia. Em 2017, cerca de 50 pessoas, incluindo militares e membros do partido, foram executadas por terem assistido novelas sul coreanas ${ }^{12}$. A existência dessas punições fatais parece ser verdadeira e se sustentar para além dos relatos de refugiados. Nas histórias narradas por

bandeadas, para sequestradas, traficadas ou refugiadas, dependendo da conjuntura nacional e política. Entretanto, a autora argumenta que, apesar de todas as dificuldades, há certo protagonismo dessas mulheres no sentido de fazerem escolhas conscientes, dentro de um leque muito limitado de opções, quanto ao seu futuro, de permanecer na China ou tentar chegar à Coreia do Sul.

12 Informações sobre todas essas execuções estão largamente disponíveis em veículos de mídia, incluindo os portais R7, G1, Uol e Terra. Alguns exemplos: Acusado de traição, tio do ditador da Coreia do Norte é executado: Jang Song-Thaek era considerado o número 2 no poder. Ex-mentor do jovem Kim Jong-Un foi condenado por um tribunal militar. Portal G1. 12/dez/3013. Disponivel em: <http://g1.globo.com/mundo/noticia/2013/12/tio-do-lider-da-coreia-do-norte-e-executado-acusado-de-traicao.html>. Acesso em: 15 nov. 2017. Ministro da Defesa da Coreia do Norte é 'executado com tiro antiaéreo'. Portal BBC. 13/maio/2015. Disponível em: <http://www.bbc.com/portuguese/ noticias/2015/05/150513 coreiadonorte execucao hb>. Acesso em: 15 nov. 2017. Coreia do Norte fuzila membros do governo por assistirem novelas. Entre os mortos estão militares e integrantes do mesmo partido a que pertence Kim Jong-un. Portal Correio 24 Horas. 30/out/2014. Disponivel em: <http://www.correio24horas.com.br/noticia/nid/coreia-do-norte-fuzila-membros-do-governo-por-assistirem-novelas/>. Acesso em: 15 nov. 2017. eles, todavia, os eventos assumiram formas muitas vezes inventivas e hiperbólicas.

A esse respeito, vemos que as execuções públicas são insistentemente mencionadas por desertores, incluindo Shin Dong-hyuk, que nasceu em um campo de prisioneiros políticos. A história dele também foi alvo de polêmica, quando suas memórias foram publicadas no livro de Blane Harden, denunciando detalhes da prisão da qual Shin escapou (HARDEN, 2012). Muito se questionou sobre a precisão do seu depoimento quanto a aspectos como a tortura e as execuções dentro da prisão. Entretanto, as várias entrevistas que Dong-hyuk concedeu são coerentes entre si e descrevem claramente as agruras às quais foi submetido e toda a violência que viu na prisão. Os questionamentos foram sustentados principalmente por um vídeo gravado na Coreia do Norte, não se sabe em que condições, no qual seu suposto pai desmentia várias de suas declarações. Para além da questão da "verdade", seu depoimento reafirma pontos presentes na memória coletiva dos refugiados, tais como o extremo controle sobre a vida individual na Coreia do Norte, as execuções e a vivência da fome.

Seu testemunho é particularmente chocante porque ele nasceu e passou toda a sua vida em um campo de trabalhos forçados, no norte da RPCN, tendo conseguido escapar pela fronteira chinesa. Acredita-se que ele tenha sido a única pessoa a lograr a fuga de um desses campos de prisioneiros. Dong-hyuk conta que viu sua mãe e irmão serem executados em sua frente, após tê-los delatado aos seus superiores. Em entrevistas, explicou que a delação era um dever e que ele não tinha a dimensão moral de que isso seria um erro. Essa noção de certo e errado só foi adquirida por ele, ao conviver com famílias da Coreia do Sul. Hoje, Shin é um importante ativista de direitos humanos. Ele também afirmou ter presenciado execuções públicas. 
Eunsun Kim, no livro A Thousand Miles to Freedom (KIM; FALLETTI, 2016), expôs a fome que sua família enfrentou na Coreia do Norte e sua fuga em direção à China, onde caiu nas mãos de traficantes de seres humanos. Eunsun chegou a ser devolvida à Coreia do Norte uma vez e foi enviada para um campo de trabalhos forçados, mas conseguiu sair e fugir novamente para a China. Foi lá que permaneceu ilegalmente por nove anos, até conseguir ir para a Coreia do Sul (KIM; FALLETTI, 2016). Sobre as execuções públicas, ela conta no livro que sua escola promovia viagens para assistirem a esses eventos. Em uma das suas descrições, está a seguinte frase:

Uma manhã na escola primária, a professora nos disse que íamos a um importante evento para nossa educação: a execução de um homem que havia cometido crimes graves. 0 playground ficou todo agitado. [...] Eu também me lembro de um homem que foi condenado à execução por ter ofendido o Grande Lider Kim Il-sung. (KIM; FALLETTI, 2016, p. 113; 115)

Como nos outros casos, esse relato parece confirmar o que foi narrado por Yeonmi, a respeito das execuções, de que elas eram públicas.

Outro exemplo contundente de deserção é o de Thae Yong-ho, ex-diplomata da Coreia do Norte que trabalhou 10 anos no Reino Unido e que, em 2016, fugiu com sua família para a Coreia do Sul, sendo o funcionário mais graduado a escapar da RPCN. Ele alegou que queria um futuro melhor para seus filhos. A propósito, em entrevista à Rede Aljazeera, à mesma repórter que questionou a história de Yeonmi, ele também mencionou as execuções públicas:

Hoje, o povo norte-coreano vive em constante medo porque Kim Jong-Un pode matar até mesmo seu próprio tio em uma execução pública, o povo viu o suficiente. Então, o povo compreendeu que se ele podia ir tão longe matando seu próprio tio, isso significava que ele podia matar qualquer um. Então, o povo vive em grande medo, essa é a primeira coisa. (JOLLEY, 2017, on -line, Tradução nossa) $)^{13}$

Vemos, portanto, a frequência com que as execuções aparecem nas narrativas, constituindo-se em um importante elemento da memória coletiva dos refugiados.

Não é possivel mensurar quantos são os relatos de refugiados norte-coreanos que descrevem a vida na Coreia do Norte e que expõem nas redes sociais, e em outros veículos de comunicação, as violações das liberdades individuais no país, incluindo execuções e prisões em campos de trabalhos forçados. São inúmeros testemunhos publicados em livros, divulgados em websites (como o Youtube ${ }^{14}$ ou as páginas virtuais de organizações de direitos humanos voltadas a esse grupo ${ }^{15}$ ) e na própria TV. Essas histórias são complementadas por outras experiências de estrangeiros que residiram no país ${ }^{16}$ - pelos mais diversos motivos e por histórias de pessoas que ficaram retidas na RPCN, por alguns anos, como foi o caso de Charles Jenkins que, se juntando a outros três soldados americanos, desertou da Guerra das Coreias, atravessando a Zona Desmilitarizada, em 1965. Os quatro desertores acreditavam que de lá seriam enviados à União Soviética, mas acabaram ficando retidos na Coreia do Norte durante mais de 40 anos (JENKINS; FREDERICK, 2008).

13 No original: "The North Korean people these days are in great fear because Kim Jong-un even killed his uncle, and when he killed his uncle he made this execution open and public, so people saw enough. So, when people learnt that Kim Jong-un even went as far as to kill his uncle, then that means that he could kill anyone. So people are in great fear, that's the first thing".

14 Disponivel em: <www.youtube.com.br>.

15 Um exemplo é a European Alliance for Human Rights in North Korea (https://www.eahrnk.org/).

16 São os casos, entre outros, de Felix Abt, empresário suiço que tem empresas e investimentos na Coreia do Norte; de Jaka Parker, jornalista indonésio que vive no país; do já falecido britânico Andrew Halloway, que passou um ano como tradutor em Pyongyang, em 1980; e de Monique Macias, filha do ex-ditador da Guiné Equatorial, Francisco Macias, e que foi criada na Coreia do Norte, entre 1979 e 1994. 
Os relatos contidos no livro da jornalista Bárbara Demick (2013) também reforçam todos os elementos da memória coletiva do exílio desses refugiados (especialmente sobre as execuções e sobre a fome). Esses casos não serão citados aqui, por não ficar clara a metodologia utilizada pela autora, tendo em vista que todas as histórias são narradas na terceira pessoa, de modo que os filtros da memória podem ter sido muito amplificados.

No conjunto dos relatos de refugiados norte-coreanos, percebemos que as incoerências da história de Yeonmi são pequenas confusões, infinitamente menos importantes do que os significados dos fatos relatados, os quais coincidem com os de outros refugiados ou de ex-residentes do país. Usamos aqui os exemplos das execuções e da fome, muito frequentes nas narrativas, que são recorrentes em suas memórias coletivas. Essas lembranças nos mostram que há uma construção simbólica sobre o passado comum desses fugitivos. $\mathrm{E}$, por meio dela, eles se reconhecem como iguais e podem ressignificar seu passado e afirmar sua identidade no novo destino.

São recorrentes, também, na sua memória coletiva, os temas da exploração dos chineses sobre os refugiados norte-coreanos e as constantes ameaças de deportação; a venda de mulheres norte-coreanas para homens chineses que precisam de uma esposa; a constante vigilância que o governo norte-coreano impõe aos seus cidadãos; a existência de campos de trabalhos forçados como punição para quem infringe as regras do governo; o desaparecimento de indivíduos ou famílias inteiras sem explicação; a existência de castas privilegiadas de cidadãos fundamentadas na proximidade e lealdade à dinastia Kim; a doutrinação cega imposta ao cotidiano dos cidadãos do país; as dificuldades de acesso a informações e a produtos do mundo exterior; e, especialmente, a fome e as execuções. Es- ses são alguns dos exemplos de lembranças que se repetem nos relatos analisados, ainda que em tons diferentes, que indicam que há elementos nas narrativas que podem até apontar para alguma verdade factual, ainda que isso seja pouco relevante, tendo em vista o significado dessas lembranças para a identidade dos desertores.

As lembranças compartilhadas por esses refugiados os ajudam a construir uma identidade que "é a consciência do eu que, com o passar do tempo, construímos através da interação com outras pessoas e com nossa vivência" (THOMSON, 1997, p. 57). São elas que permitem o compartilhamento de experiências e que dão a eles a sensação de pertencimento. Sobre as incoerências dessas narrativas, nos remetemos às palavras de Roseman (2000, p. 131-132):

O que significam essas diferenças? Parece bastante claro que as mudanças [nas narrativas] ocorreram em momentos de grande trauma. [...] Em outras palavras, as discrepâncias sugerem que, onde sua experiência foi mais traumáti$\mathrm{ca}$, o trauma resultou numa incapacidade de enfrentar as lembranças tais como eram, uma pressão que levou, de um lado, a uma inapetência de falar sobre isso com o mundo exterior, e, de outro, a esse processo de mudanças sutis.

Assim, podemos aventar a possibilidade de que os exageros nos relatos ajudam aqueles que testemunham a lidar com os traumas de seu passado, para que possam continuar seguindo em frente.

De forma similar aos relatos ouvidos na pesquisa de Roseman (2000), a história de Yeonmi também foi moldada por "exageros e incoerências" (que foram impiedosamente apontados pela jornalista Jolley como indícios de mentira). Poderíamos, entretanto, subverter essa ideia de mentira, para entendermos tais confusões como recursos subjetivos que ajudam na elaboração de uma difícil realidade 
vivida. Roseman (2000) analisou o papel da veracidade das histórias, tendo por base um estudo que fez com sobreviventes do holocausto, em especial com uma depoente que não havia sido enviada aos campos de concentração. Segundo o autor, era justamente nos eventos mais dramáticos ou traumáticos que a memória da entrevistada exagerava nos acontecimentos, o que também pareceu ser o caso de Yeonmi e dos relatos aqui analisados.

Não há dúvidas sobre o tom fantasioso dos relatos desses refugiados. Mas também podemos estar certos de que existem fatos concretos sendo revelados por essas histórias, que são o substrato das fantasias e exageros, como no caso das execuções. Não se trata, entretanto, de fatos "verdadeiros" ou "mentirosos", mas sim de elementos concretos que moldam a vivência comum de um grupo e a sua identidade. Há essa distância entre o vivido e o narrado, entre o que aconteceu e o que foi lembrado, que precisa ser compreendida para chegarmos à complexidade do fato histórico. Essa distância pode ser entendida como o local do simbólico, das construções subjetivas e da memória coletiva, espaço onde se constrói e se afirma a identidade do grupo e as suas próprias verdades (que são sempre heterogêneas, no processo histórico).

Os exageros no relato de Yeonmi e de outros refugiados cumpririam duas funções: uma social, dentro da moldura da memória coletiva, afirmando o heroísmo dos desertores, ao denunciarem as mazelas de seu país; outra subjetiva, de fornecer a si mesmos um amparo ancestral, para orientar e dar um sentido a suas vidas, em meio às dificuldades do exílio e da vida pregressa no país de origem.

\section{Considerações finais}

Por que esses exemplos interessam à história oral? Essas histórias de refugiados norte-co- reanos nos ajudam, primeiramente, a refletir sobre a falsa centralidade da ideia de verdade, de precisão e de confiabilidade das histórias, temas estes que são centrais ao debate de quem trabalha com a oralidade.

Uma primeira consideração metodológica que emerge desse debate é que a combinação de fontes sempre nos auxilia a lidar com as dificuldades impostas pelo problema da precisão das narrativas. Outra, é que a diversidade de visões que aparece em dados diferentes não necessariamente torna a fonte oral mentirosa, apenas mostra outros pontos de vista, outra interpretação sobre os eventos, isto é, que a História comporta a multiplicidade de discursos sobre si própria.

Examinando a situação desses refugiados pelo prisma da história oral, podemos verificar que a acuidade de seus relatos é pouco relevante, se for analisada a construção discursiva pela ótica do processo de afirmação da identidade. A memória permite uma elaboração subjetiva feita no presente sobre o que foi o passado, mas não revela o passado exatamente como aconteceu.

Trata-se de analisar como as lembranças expressam o compartilhamento de situações que somente quem percorreu o trajeto da Coreia do Norte até a do Sul pode ter vivenciado. A memória coletiva, com suas inconsistências e imprecisões - porque toda narrativa é construção e porque as lembranças não são neutras, mas interagem com o presente (dizem mais sobre o presente do que sobre o passado) -, tem como função a consolidação do pertencimento a uma tragédia comum aos refugiados, e também visa alertar o mundo sobre as perseguições vividas em um regime que, de tão fechado, tem como única fonte de informações justamente esses depoimentos.

Tais posturas metodológicas não implicam negarmos fatos e muito menos minimizarmos a importância de outras fontes históricas. Pelo 
contrário, o esforço do pesquisador deve consistir em entender o mosaico de visões históricas e o significado da diversidade de suas fontes.

A segunda observação é que não precisamos nos perguntar se as histórias dos desertores norte-coreanos são mentirosas (e tampouco precisamos nos perguntar se são verdadeiras, vem pouco ao caso), mas precisamos entendê-las como parte das muitas peças que compõem sua memória coletiva. São fragmentos que eles juntam para afirmar sua identidade de refugiados e para contestar a manipulação identitária operada pelos países por onde passam, durante sua fuga (de imigrantes econômicos ou ambientais). Há, portanto, protagonismo nesses relatos autobiográficos, para além da vitimização (mesmo que eles pareçam descrever situações exageradas).

O terceiro aspecto que vale pensarmos é sobre o papel desses relatos autobiográficos na construção de uma história pública (SANTHIAGO, 2013). Isto pode ser constatado na produção de registros feita pelos próprios refugiados sobre as perseguições e a fome que vivenciaram na Coreia do Norte e sobre as dificuldades nos países por onde passaram, após sua fuga.

A diversidade de fontes midiáticas que divulgam essas histórias e a disposição de inúmeros refugiados de contar suas experiências, mesmo correndo o risco de ocasionar perseguições a suas famílias que ainda vivem na Coreia do Norte, refletem iniciativas individuais e coletivas de constituição de um acervo ainda difuso de história pública feita pelo público (como é o caso do acervo on-line de histórias da Ong Liberty in North Korea ${ }^{17}$ ), ou seja, fora dos muros da academia:

De origem anglo-saxã, o termo história pública procura dar conta, de uma forma ampla,

17 Disponivel em: <https://www.libertyinnorthkorea. org/blog/category/refugee-stories/>. Acesso em: 20 nov. 2017. das relações e do diálogo entre a produção acadêmica e não acadêmica do conhecimento histórico. De um lado, os lugares de produção de saber histórico se multiplicaram, indo além dos departamentos e centros universitários. De outro, as numerosas contendas sobre a memória coletiva e o dever de memória têm frequentemente colocado a disciplina histórica no centro de debates públicos com amplas repercussões políticas e sociais. Tais fenômenos refletem-se na vasta produção editorial, audiovisual, museológica, entre outras, que mobiliza saberes históricos, articulando demandas por esse tipo de conhecimento vindas de diversos setores da sociedade civil e do Estado. (EDITORIAL, 2014, p. 229)

A produção de um acervo de relatos autobiográficos e de entrevistas por esses desertores norte-coreanos revela um esforço de valorização de sua vivência comum e também de subversão dos estereótipos identitários que lhes são impostos, especialmente pelos países que thes negam o status de refugiados.

Arrematando o artigo e respondendo às nossas inquirições iniciais, podemos afirmar que as histórias autobiográficas de refugiados norte-coreanos nem sempre são precisas. Há inúmeros elementos que interferem na forma como suas lembranças são evocadas. As inconsistências, no entanto, parecem indicar espaços da memória coletiva que têm a função de marcar a resistência; de construir e de legitimar sua identidade como refugiados, em contraposição aos estereótipos que os países receptores a eles reservam: são refugiados, não imigrantes econômicos. Assim, com a diversidade e a quantidade de relatos autobiográficos que essa comunidade vem produzindo e dispondo ao grande público, pode-se afirmar que existe uma iniciativa importante de história pública sendo germinada, iniciativa que tem como meta a denúncia e a apropriação de sua própria narrativa histórica. 


\section{Referências}

AMADO, Janaína. O Grande Mentiroso. História, São Paulo, n. 14, p. 125-136, 1995.

BOSI, Ecléa. Sugestão para um jovem pesquisador. In: . 0 tempo vivo da memória. São Paulo: Ateliê Editorial, 2003. p. 49-57.

BOSI, Ecléa. A pesquisa em memória social. Psicol. USP, v. 4, n. 12, p. 277-284, 1993.

DEMARTINI, Zeila. Relatos orais, documentos escritos e imagens: fontes complementares na pesquisa sobre imigração. In: TRINDADE, M.; CAMPOS, M. C. (Orgs.). História, memória e imagens nas migrações: Abordagens metodológicas. Oeiras: Celta Editora, 2005. p. 99-134.

DEMICK, Bárbara. Nada a invejar. Vidas comuns na Coréia do Norte. São Paulo: Cia. das Letras, 2013.

EDITORIAL. História pública Estud. hist. (Rio J.), Rio de Janeiro, v. 27, n. 54, p. 229-230, dez. 2014. Disponível em: <http://www.scielo.br/scielo.php?script=sci arttext\&pid=S0103-21862014000200229>. Acesso em: 20 nov. 2017.

GAHNG, Elisa. North Korean Border-Crossers in Yanbian: The Protection Gap between the Economic Migrant and Refugee Regimes. Georgetown Immigration Law Journal, v. 24, n. 2, p. 361-378, winter 2010.

HALBWACHS, M. Memória individual e memória coletiva. In: A memória coletiva. São Paulo: Centauro, 2006. p. 29-70.

HARDEN, Blane. Escape from camp 14: one man's remarkable odyssey from North Korea to freedom in the West. New York: Penguin Books, 2012.

JENKINS, Charles; FREDERICK, Jim. The reluctant communist: my desertion, court-martial, and forty -year imprisonment in North Korea. Oakland: University of California Press, 2008. 192 p.

JOLLEY, Mary Ann. The strange tale of Yeonmi Park: a high-profile north korean defector has harrowing stories to tell. But are they true? The Diplomat. 10/dez/2014. Disponivel em: <http://thediplomat. com/2014/12/the-strange-tale-of-yeonmi-park/>. Acesso em: 03 mar. 2017.
Thae Yong-ho: interview with a north ko-

rean defector. Aljazeera. 10/maio/2017. Disponivel em: <http://www.aljazeera.com/programmes/101east/2017/05/thae-yong-ho-interview-north-korean-defector-170503114811043.html>. Acesso em: 15 nov. 2017.

KIM, Eunsun; FALLETTI, Sebastian. A thousand milles to freedom: my scapt from North Korea. New York: St. Martin's Griffin Press, 2016. 228 p.

KIM, E. Tammy. Escape from DPRK: how Yeonmi Park, a north korean defector, became a controversial globe-trotting celebrity on the stage of international human rights. The Nation. Nova York. 11/ fev/2016. Disponivel em: <https://www.thenation. com/article/escape-from-the-dprk/>. Acesso em: 14 nov. 2017.

KOTRE, John. Luvas brancas: como criamos a nós mesmos através da memória. São Paulo: Mandarin, 1997. 265 p.

KOTRE, John. A Verdade e Utilidade das Histórias. In: Santhiago, Ricardo; Magalhães, Valéria (org.) Depois da utopia: A história oral em seu tempo. São Paulo: Letra e Voz, 2013. p. 29-38.

LANKOV, Andrei. The real North Korea: life and politics in the failed stalinist utopia. Okford: Oxford University Press, 2013.

MAGALHÃES, Valéria; SANTHIAGO, Ricardo. (Orgs.). Depois da utopia: a história oral em seu tempo. São Paulo: Letra e Voz, 2013. p. 29-38.

PARK, Yeonmi. Para poder viver. Cia. das Letras, 2016. 308 p.

Yeonmi Park Speech. One Young World

Summit. Dublin: One Young World, 2014. Disponivel em: <https://www.oneyoungworld.com/news-item/ yeonmi-park-speaks-united-nations-30th-human -rights-council-meeting-north-korea>. Acesso em: 20 fev. 2018.

PASSERINI, Luisa. A memória entre a política e a emoção. São Paulo: Letra e Voz, 2011. 240 p.

PATAI, Daphne. Verdade e mentira sob fogo cruzado: pedindo desculpas pelo testemunho de Rigoberta Menchú. In: SANTHIAGO, Ricardo; MAGALHÃES, Valé- 
ria. (Orgs.). Depois da utopia: a história oral em seu tempo. São Paulo: Letra e Voz, 2013. p. 165-186.

PORTELLI, Alessandro. O que faz a história oral diferente? Revista Projeto História, v. 14, p. 25 - 39, fev. 1997.

Sulla diversità della stori orale. Primo Maggio, n. 13, 1979, p. 54-60.

ROSEMAN, Mark. Memória sobrevivente: verdade e inexatidão nos depoimentos sobre o holocausto. In: FERREIRA, Marieta. (Org.). História oral: desafios para o século XX. Rio de Janeiro: Fiocruz, 2000. p. 122-134. Disponível em: <https://www.arca.fiocruz. $\mathrm{br} /$ bitstream/icict/2707/1/Ferreira Fernandes Alberti.pdf>. Acesso em: 06 mar. 2018.

SANTHIAGO, Ricardo. História oral e história pública: museus, livros e a "cultura das bordas". In: SANTHIAGO, Ricardo; MAGALHÃES, Valéria. (Orgs.). Depois da utopia: a história oral em seu tempo. São Paulo: Letra e Voz, 2013. p. 131-140.

SONG, Jiyoung. Twenty years evolution of North Ko- rean migration, 1994-2014: a human security perspective. Asia and the Pacific Policy Studies, v. 2, n. 2, p. 399-415, mai. 2015a.

Why do North Korean defector testimonies so often fall apart? Cash incentives and the western media's endless appetite for shocking stories encourage refugees to exaggerate. The Guardian. 13/out/2015b. Disponivel em: <https://www.theguardian.com/world/2015/oct/13/why-do-north -korean-defector-testimonies-so-often-fall-apart>. Acesso em: 20 nov. 2017.

"Smuggled refugees": the social construction of North Korean migration. Int Migr., v. 51, n. 4, p. 158-173, 2013. Disponível em: <http://onlinelibrary.wiley.com/doi/10.1111/imig.12033/full>. Acesso em: 21 nov. 2017.

THOMSON, Alistair. Recompondo a memória: questões sobre a relação entre a História Oral e as Memórias. Projeto História, São Paulo, n. 15, p. 51-84, abr. 1997.

Recebido em: 22.11.2017 Aprovado em: 02.03.2018

Valéria Barbosa de Magalhães é Doutora em História Social. Docente da Escola de Artes, Ciências e Humanidades da Universidade de São Paulo, EACH/USP e do Programa de Pós-Graduação em Estudos Culturais da USP. e-mail: gephom@gmail.com

EACH/USP. Avenida Arlindo Bettio, 1000. Ermelino Matarazzo, São Paulo/SP. CEP: 03828-000. Telefone: (11) 3091.8881 